\title{
Back Pain, Causes, Symptoms and Physiotherapy
}

\section{Karski Tomasz ${ }^{1 *}$, Karski Jacek², Karska Klaudia ${ }^{3}$, Ramirez Claudia $^{4}$,}

\section{Kedzierski Zbigniew 5 and Menet Honorata ${ }^{6}$}

1Vincent Pol University, Lublin, Poland

${ }^{2}$ Pediatric Orthopedic and Rehabilitation Department of Medical University, Lublin,

Poland

${ }^{3}$ Radiology Department of Medical University, Lublin, Poland

${ }^{4}$ An American Student of the Medical University in Lublin, Poland

${ }^{5}$ Orthopedic Research Center, Lublin, Poland

${ }^{6}$ Student of University in Caen, France

*Corresponding author: Tomasz Karski, Professor Lecturer in Vincent Pol University, Lublin, Poland, Email: tmkarski@gmail.com ; t.karski@neostrada.pl

\section{Abstract}

Every fourth woman and every sixth man in the world coming to the Orthopedic or Neurology Departments complain of spinal pains - information from WHO, Decade of Bones and Joints 2000-2010 (Lars Lidgren). According to our observations there are six main causes of such spinal disorders:

1. Lumbar Hyperlordosis causes by flexion contracture of hips and in result anterior tilt of the pelvis. Common in persons with Minimal Brain Dysfunction (MBD). Pain syndromes appear after overstress in some kinds of jobs or in sport.

2. Lumbar or thoracic-lumbar left convex "C" scoliosis in 2nd/A etiopathological group (epg) or "S" scoliosis in 2nd/B epg in Lublin classification. Pain syndromes appear after overstress in some kinds of jobs or in sport.

3. Stiffness of the spine as clinical sign of "I" scoliosis in 3rd epg group in Lublin classification.

4. Spondylolisthesis or spodylolisis in sacral-lumbar or lumbar spine.

5. Urgent "nucleus prolapsed" (in German "Hexen Schuss").

6. Extremely cooling of the back part of trunk during work or intensive walking in low temperature.

In many of patients in clinical examination we see positive Laseguae test. Sometimes we see weakness of extensors of the feet or paresis of the foot.

Our observations confirm that not surgery, but physiotherapy can be beneficial to the patients with spinal problems.

Keywords: Back Pain; Causes; Physiotherapy

\section{Introduction}

In literature are presented various cause of back pain [1-16]. In article we describe the causes of the back pain according ours observations [5,7,8-15]. We describe also the possibility and effectiveness of physiotherapy of the back pain syndrome. The cases presented below inform about symptoms and described pathology of spine from 


\section{Journal of Orthopedics \& Bone Disorders}

orthopedic point of view. We present details of ours physiotherapy methods and inform about the effectiveness of treatment and prophylactics.

\section{In the Article we Describe Six Causal Groups of Patients with Back Pain}

Back pain Cause - Hyperlordosis of lumbar spine (Figures 1a, 1b \& 2): On the first place of causes of "the back pain" is a Hyperlordosis of the lumbar spine, or sacral lumbar spine or lumbar thoracic spine.

This deformity is connected with the hips flexion contracture and in result with anterior tilt of the pelvis, next with the "Hyperlordosis of lower part of spine". This deformity, develop in three levels-hips, pelvis, spine. The primary cause of "the back pain" is Minimal Brain Dysfunction (MBD) in newborn, babies and next if not treated - in adolescents and adults time of life is the cause of healthy problems. MBD is caused by incorrect pregnancy and not proper and not save delivery. Such MBD illnesses we see in Poland in about $12 \%$ of children [15]. The anterior tilt of pelvis is due to semi-spastic shortening of $\mathrm{m}$. rectus on both sides. At the same time the children, and next older people, have the general laxity of joints, because of changed properties of collagen and not because of "weak muscles" what is popular with doctors in Poland. Till now we do not know the method to change collagen, so the laxity persists through all years of life. Secondary appears lumbar hyperlordosis resulting in incorrect positioning of the spine which make permanently pressure on nerve roots which leads to "syndrome of chronic back pain".

In some patients we see also deformity in level of shoulders. It is "the forward position of the shoulders", next Hyperlordosis of cervical spine, hyperkyphosis in thoracic spine and compensatory Hyperlordosis in the lumbar spine.

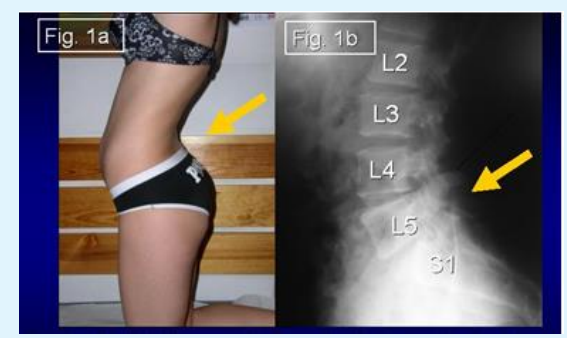

Figures 1a, 1b: Girl 13 years old. Example of anterior tilt of pelvis as result of flexion contracture of the hips. Sacral bone horizontal position. In result Hyperlordosis of lumbar spine (arrows). If this deformity is not treated in childhood in adults age back pain.

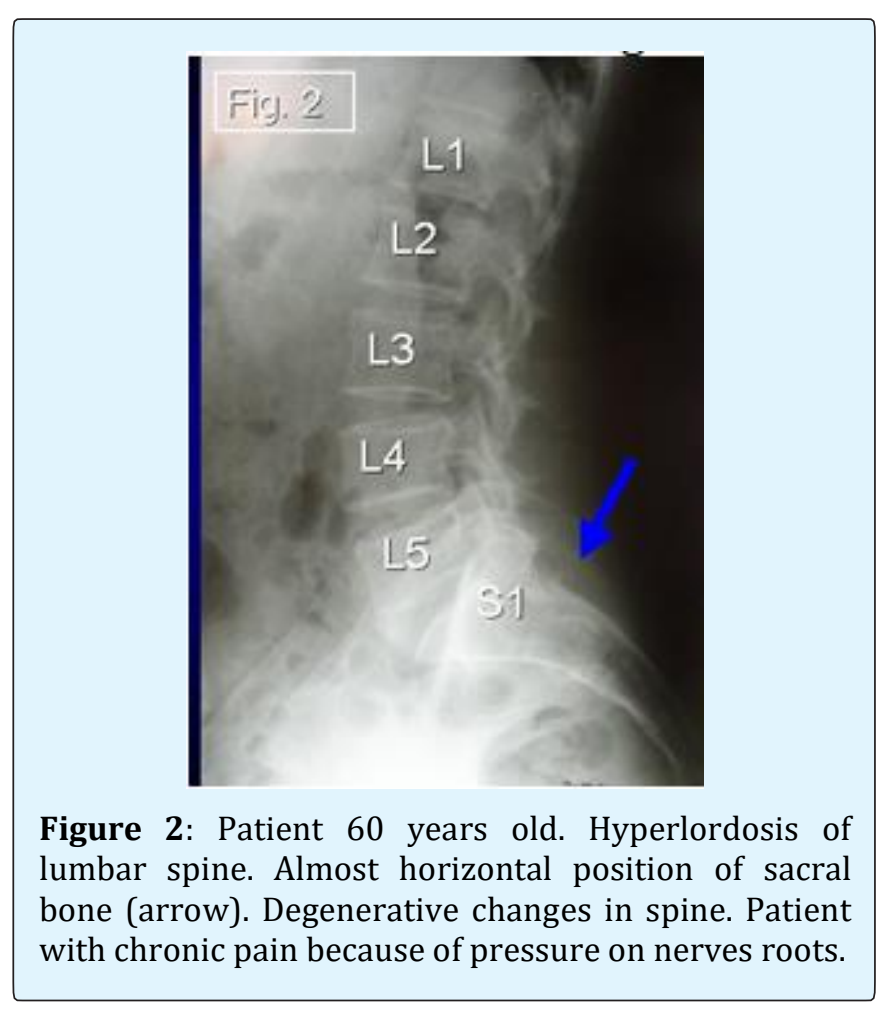

Back pain. Cause - degenerative lumbar, or lumbar thoracic left convex curve (Figures 3a, 3b): In this group of patients the "back pain" in causes by so-called idiopathic scoliosis. This deformity in Lublin new classification $[8,9,10-15]$ belong to the 2nd A \& 2nd B etiopathological group (epg). The "C" or "S" curves of the spine are connected with the special model of hip movements and next with "permanent standing 'at ease' on the right leg". According to the new knowledge about spine this deformity start to develop from the 2 nd year of life. The primary cause is connected with asymmetry of hips movement - it means adduction in straight position of right hip joint is limited. This asymmetry is connected with the Syndrome of Contractures and Deformities $(\mathrm{H}$. $\mathrm{Mau}$ ). The adduction of the right hips in straight position of joint is limited. This hip joint is more stable and right leg is taken for permanent standing 'at ease'. Standing on the right leg is more stable, more comfortable than standing on the left leg and is taken not only for children and youth, but also for adults for all years of life. After 1012 years of such standing develop the fixed lumbar or sacral lumbar or lumbar thoracic left convex curve. After next years of the standing on the right leg - the scoliosis become to be "degenerative scoliosis" and manifest not only as deformity but also as the recurrent back pain. The pain is because of pressure on the nerve roots in concave part of spine or on pulling of the roots in convex part of spine. Long observation $(1984-2019)$ indicates that the "pulling of the roots" on the left convex side of spine is 


\section{Journal of Orthopedics \& Bone Disorders}

more frequent cause of a pain. In some cases the result of such pulling can appear even as paresis of the foot dropping down of the foot.

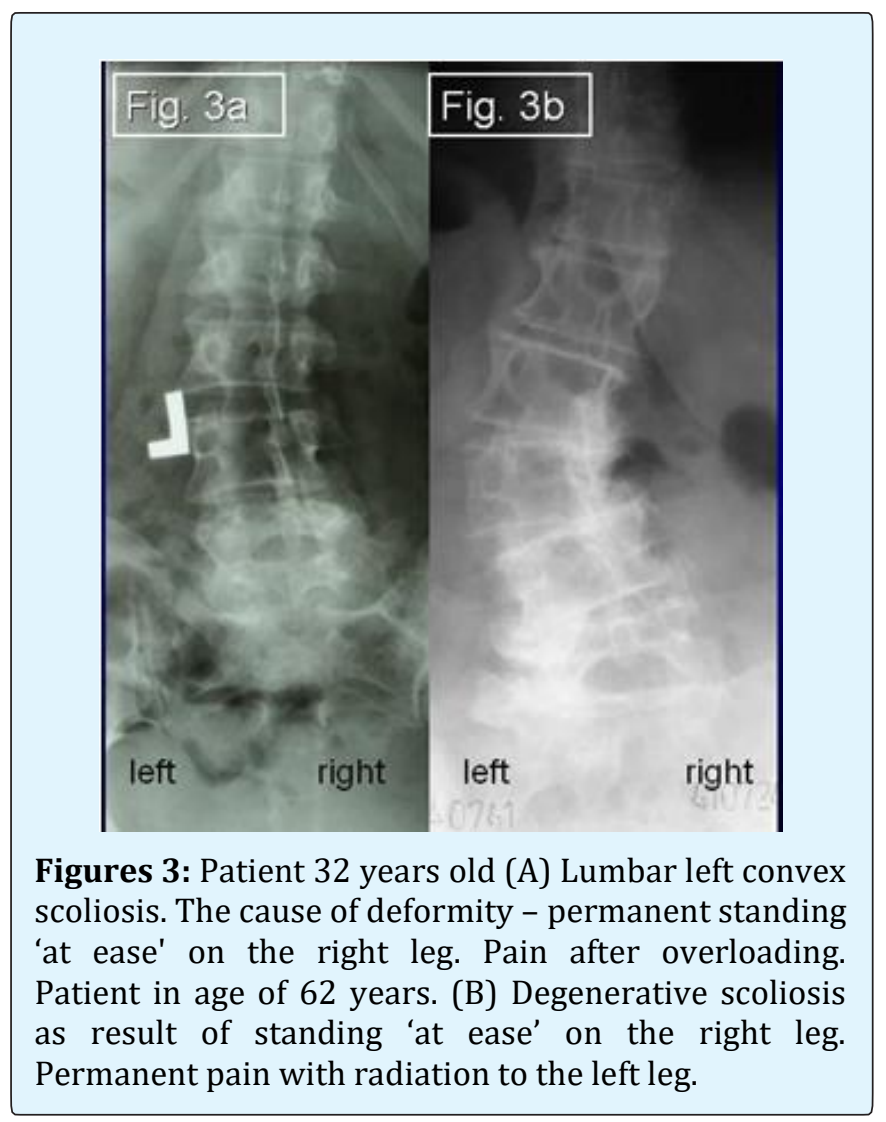

Back pain. Cause - stiffness of the spine (Figure 4): In this group "the back pain" is connected with the stiffness of the spine. This deformity belongs to scoliosis in $3^{\text {rd }}$ epg group in Lublin classification.

The spine deformity is connected with the special model of hip movements and next with "gait". In situation of maximal limited adduction movement of the right hip and limited movement of the left hip (examination in straight position of joints) - during gait the "absent movement of hip or hips" is transmitted to the pelvis and to the spine as bigger than normal rotation movement. In results of this rotation movement appears distortions in inter-vertebral joints and in result stiffness of the spine.

In every day - in home or in job activity we need full movement of the body and of the spine. The stiffness of the spine disturbed this activity and if the movement is not present "pain's distensions symptoms" appeared.

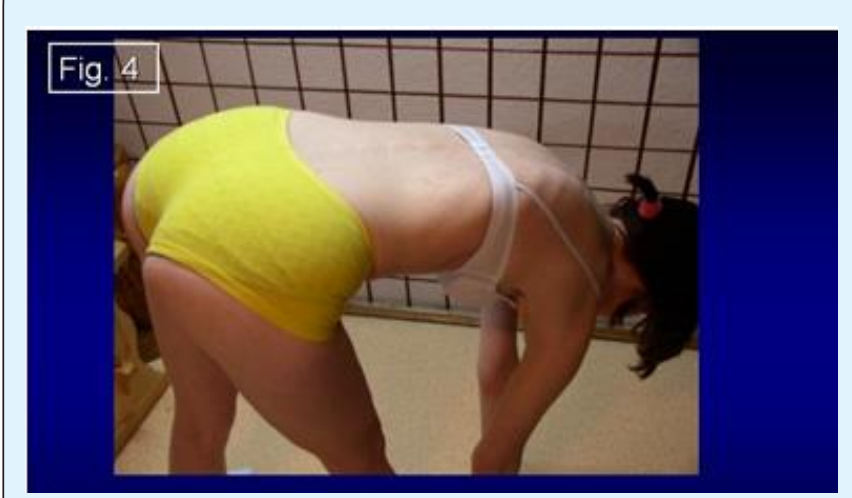

Figure 4: Patient 21 years old. $3^{\text {rd }}$ epg group of scoliosis in new classification. Stiffness of the spine. Such deformity included to scoliosis group in 2004. Young people - problem in sport. Adults - pain in every day activity.

Back Pain. Causes - spondylolisis or spondylolisthesis : In this group the pain is because of dislocation of vertebra bodies mostly in the connection of L5 and S1, in some cause between L4 and L5, in other cases in two levels L4 - L5 - S1. The cause of spondylolisthesis can be congenital or acquisitioned. This second form is mostly after overloading of lumbar part of spine in special hard form of work in industry, in farmers work etc.

Back pain - urgent and acute "prolapsed nucleus": Patients in this group belong to the group with "Hyperlordosis of lumbar spine" and to group with "degenerative left convex lumbar scoliosis". In older age, during hard work can appear "acute back pain syndrome" in lower part of spine. The annoying pain can be in lumbar or sacral - lumbar part of spine. The movement in this part of spine "in pain time" is totally limited. Because the pain can be in the backs side on hip level - very often it confuse the patients or even doctors - they diagnoses hips problem. The pain can radiate to the left or to the right leg - but in all cases is present in back part of thigh, next in lateral part of shank, in dorsal side of foot.

The urgent and acute "the prolapsed nucleus" can appear in cervical part of spine. The annoying pain is on left or on right side of neck. The pain can radiate to the left or to the right shoulder, arm, even to elbow or to the scapula region. The movement of cervical part of spine is very painful and totally limited. Even elevation of upper extremity is painful. The cause of "pain syndromes in cervical part of spine" is endezo-pathies, after a long time working with computer, or in drivers of Lorries. 


\section{Journal of Orthopedics \& Bone Disorders}

Some patients with the back pain because of acute "prolapsed nucleus" need surgery if the physiotherapy in 2-3 weeks is without success.

Extremely cooling of the back part of trunk during work or intensive walking in low temperature: Jogging or intensive walking longer time in low temperature can be the cause of "muscle pain". In this group the pain disappears after resting, warming of back part of the body and gentle massage.

Back pain occurs very often in these patients who are in situation of "overstress in some kinds of jobs or in sport". Even patients alone see the connection with the overstress in the job. The pain is moderate or acute. This group of patients is coming from "building group workers", workers of mine or "road group workers". The muscle pain after resting can disappear. It helps also warming of the effected parts of the body and gentle massage of the spine.

\section{Material}

The whole material counts 286 patients. 68 younger patients were admitted to the Pediatric Orthopedic and Rehabilitation Department in the years 1995-2009 (author-T. Karski was the head of this Department in these years). Age of patients of this group was 16-18 years. Other group of 218 older patients was coming to Out Patients Department of authors in the year 19952018. Age of this group of patients was 35-70 years. All patients suffered because of pain of the spine, mostly in lower part of spine. Precise diagnosis found the causes described in subchapters above-it was mostly "Hyperlordosis" and "degenerative scoliosis" of lumbar part of spine.

\section{Physiotherapy}

Very common in Poland the orthopedic surgeons or neurosurgeons recommend the surgery for patients with back pain. In our opinion, based on long years of observations - such treatment is not proper and not leading to full and long lasting good results. The causes of pain mostly are located in many levels of spine. The surgery is in one or two levels of spine. The surgeries do not give good result from first days after operation or the pain is coming again after some weeks or months. We advise for our patients the physiotherapy. The details of the therapy depend of the diagnosis. In many points there are similar for various group of patients. Only some cases, in our material $5 \%$, need surgery.

Our therapy in points:
- "Chair extension for the lumbar spine" (Figure 6). This method of therapy we learned in German and it is called: Perlsches Brett Behandlung. This method of treatment was introduced by author [Karski T.] in Poland 50 years ago, after visiting the Orthopedic Department in Leipzig in 1968. We recommend this extension method of therapy to ours patients for 20-30 minutes, five or more times every day. When heavy pain-extension should be longer time, even whole day.

- Resting and sleeping in embryo position-mostly on the right side of the body. In situation of "recurrent pain" many times 15 - 30 minutes during day.

- Very important is to inform the patients to avoid "standing 'at ease' on the right leg" in every day situations. This recommendation to stand properly is very easy and in many patients is very effective. Corrective standing in abduction and in internal rotation is especially beneficial for the spine and for the hips. Such a method of therapy was introduced in Lublin 30 years ago (about such standing two publications in USA - literature points 17,18 ).

- Flexion exercises for the spine to the front and to the left side when the essential pain disappears and especially in "lumbar left convex scoliosis".

- Gentle massage of the lumbar and thoracic part of spine.

- Physical therapy - diadynamic, jonophoresis, laser, criotherapy.

The patients with "back pain" need additionally management "against the causes". There are special exercises in "pain free period of illnesses":

- Stretching exercises to correct the position of the pelvis and to lengthen flexors of knees and of Achilles tendons together with $m$. triceps surae.

- Exercises typical for karate, taekwondo, aikido or yoga for the same aim.

- Exercise in geothermal water is an especially important - in warm water the pain disappears and effectiveness of exercises is much bigger.

After some weeks of the therapy presented in this chapter, the back pain disappeared. The patient could start working and performing daily activities. In many patients this program of therapy should be repeated. 


\section{Journal of Orthopedics \& Bone Disorders}

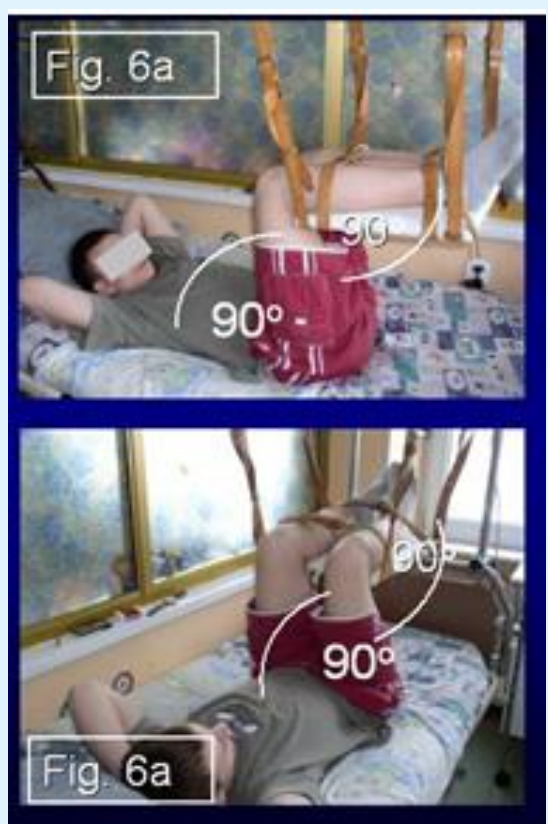

Figure 6: Chair extension therapy for the spine. The methods of therapy author (T. Karski) learned in Germany in 1968 in Orthopedic Department in Leipzig (in German - Perlsches Brett Behandlung). The therapy need long time-many days or weeks. For older patients should be repeated.

On the picture young patients in Orthopedic Department in Lublin (T. Karski - head of the Department in 1995-2009).

\section{Discussion}

In the literature are presented, but never confirmed, various reasons of spine deformity and back pain [16-25]. It is essential and important to understand that the following, presented in the paper pathological changes are really the cause of back pain. On the first plane is the anterior tilt of the pelvis with Hyperlordosis of the lumbar spine, very often connected with horizontal position of the sacral bone. On the second place is the lumbar left convex "C" scoliosis 2nd/A epg or "S" 2nd/B epg (in Lublin classification). Both types of curvatures are caused by permanent standing "at ease" on the right leg. Both types of scoliosis are also referred to a degenerative scoliosis which was confirmed during SICOT 2005 Congress in Istanbul. On the third place of back pain is the stiffness of the spine in "I" 3rd / epg scoliosis group in Lublin classification.
In last group of causes is spondylolisthesis. Even in this group we recommend physiotherapy - chair extension (Perlsches Brett Behandlung) and not surgery. The results in this group are also sufficient.

A majority of orthopedic surgeons and neurosurgeons abroad and in Poland unfortunately indicate surgery, but according ours observation it is not the best therapy.

When the diagnosis - causes of back pain - is taken into consideration, the physiotherapeutic procedures presented above will be understandable.

\section{Conclusion}

The causes of back pain are the following:

$\checkmark$ Lumbar hyperlordosis as a result of an incorrect position of the pelvis (anterior tilt of the pelvis).

$\checkmark$ "C" or "S" scoliosis in $2^{\text {nd }}$ group of spine deformity (Lublin classification).

$\checkmark$ Scoliosis in a form of stiffness in $3^{\text {rd }}$ group of spine deformity (Lublin classification).

$\checkmark$ Spondylolisthesis - congenital or acquired

$\checkmark$ Prolapsed nucleus pulpous can be the cause of acute pain in patients from various groups in point 1.

$\checkmark$ The treatment presented in subchapter "Physiotherapy" is very effective but especially important is "Chair extension for the spine" and "Resting and sleeping in embryo position".

$\checkmark$ Surgery in the treatment of spinal pain and especially in low back pain is usually unsatisfactory and gives good results only for a short time.

- The ultimate goal for orthopedic surgeons, rehabilitation doctors, and general doctors as well for physiotherapists should be:

$\checkmark$ To teach patients to stand 'at ease' only on the left leg or in both legs in abduction of 30 degrees and in internal rotation 10-20 degree to avoid scoliosis.

$\checkmark$ Prophylaxis for children through proper stretching exercises for the correct posture.

$\checkmark$ Prophylaxis and treatment of scoliosis by stretching exercises to obtain the full movement of hips, the proper position of pelvis and the full movement of the spine.

$\checkmark$ Sitting relaxed - never straight up - and resting in embryo position (see point 3 ) as a important element in prophylaxis of scoliosis.

$\checkmark$ The therapy of scoliosis should start at the age of $4-6$.

$\checkmark$ The proper ergonomic behavior of the spine during everyday activities is important. Heavy objects should only be carried on the side. 


\section{Journal of Orthopedics \& Bone Disorders}

\section{References}

1. Abbott JH, Mercer SR (2002) The natural history of acute low back pain. New Zeeland Journal of Physiotherapy 30(3): s 8-16.

2. Bazan M (2006) Pain spine and spine syndromes of the lower spine (Spine and roots pain syndromes). "Skalpel" 2006/03 (May-June) - a letter from the Military Medical Chamber in Warsaw, Rehabilitation Clinic of the Central Clinical Hospital of the Ministry of National Defense in Warsaw.

3. Domżał TM (2006) "Back pain (Family doctor)”. NR, 9: 930-941.

4. Farfan HF (1973) Mechanical disorders of the low back, Lea \& Febiger, Philadelphia.

5. Gardner A, Karski T, Skoliozy (2000) idiopatyczneprzyczyny, rozwój i utrwalanie się wady. Profilaktyka i zasady nowej rehabilitacji. The etiology of the socalled idiopathic scoliosis. Progress and fixation of the spine disorders. The prophylaxis and principles of the new rehabilitation treatment, KGM, Lublin, pp: 1-14.

6. Gasik R, Styczyński T, Pyskło B (2007) Badanie priopriorecepcji w obrębie stawów kolanowych u chorych na dyskopatię lędźwiowego odcinka kręgosłupa. Reumatologia 45(4): 186-189.

7. Karski T, Karski J, Madej J, Latalski M (2002) Persönliche Überlegungen zur Ätiologie der idiopathischen Skoliosen. Praktische Hinweise zur Entdeckung beginnender Skoliosen. Prinzipien der neuen Übungstherapie. Möglichkeiten der Prophylaxe. Orthop Praxis 38: 75-83

8. Karski T (2011) Biomechanical Etiology of The SoCalled Idiopathic Scoliosis (1995 - 2007) Connection with "Syndrome of Contractures"Fundamental Information for Pediatricians in Program of Early Prophylactics / Journal of US-China Medical Science, USA, 8(78).

9. Karski T, Kędzierski Z, Bartoszczyk A, Jabłoński M, Karski J, et al. (2012) History of orthopaedics in Lublin. Founding of the Orthopaedic Department of Medical University in 1954. Problems. The team. Didactics. Clinic and research aim in the years $1954-$ 2012, Pohybove ustroji / Locomotor System 4: 256279.

10. Karski T (2010) Factores biomechanicos en la etiologia de las escoliosis dinominadas idiopaticas.
Nueva classification. Nuevos test clinicos y nueavo tratamento conservador y profilaxis, Cuestiones de Fisioterapia, Mayo-Agosto 3(2): 85-152.

11. Karski Tomasz, Jacek Karski (2015) Biomechanical etiology of the so-called Idiopathic Scoliosis (1995 2007). Causative role of "gait" and "permanent standing 'at ease' on the right leg". New classification. Principles of new therapy and causal prophylaxis. Canadian Open Medical Science \& Medicine Journal 1(1): $1-16$

12. Karski Tomasz, Karski Jacek (2015) Syndrome of Contractures and Deformities" according to Prof. Hans Mau as Primary Cause of Hip, Neck, Shank and Spine Deformities in Babies, Youth and Adults. American Research Journal of Medicine and Surgery $1(1)$.

13. Karski Tomasz, Karski Jacek (2016) Bóle krzyżaproblem neurologiczno - ortopedyczny. Objawy. Przyczyny. Leczenie. Back pain-neurology-orthopedic problems. Clinic, causes, therapy and prophylaxis. Postępy Neurologii Praktycznej, Wydawnictwo Czelej Str, pp: 9-16

14. Karski Tomasz (2017) Physiotherapy - Correct, or Incorrect, Based on 'Wrong Principles of Treatment'. Example for Spine, Hip, Knee, Shank and Feet. Crimson Publisher, USA, Ortho Res Online, Review Article, pp: 1-4.

15. Karski Jacek, Karski Tomasz, Pyrc Jarosław, Kulka Malgorzata (2016) Deformations of the feet, knees, hips, pelvis in children and adults with minimal brain dysfunction. Causes. Treatment. Prophylaxis. Locomotor System 23.

16. Tomasz Karski, Jacek Karski Karate, Taekwondo, Aikido, Kung Fu (2017) Yoga and Other Far Easter Forms of Activities-are not only Sport but also the best Method of Treatment of Locomotor's System Deformities. Journal of Yoga 2017(4): 1-8.

17. Karski Jacek, Karski Tomasz (2016) "Imperfect hips" As a Problem at an Older Age. Early and Late Prophylactic Management before Arthrosis. Jacobs Journal of Physiotherapy and Exercises / USA / Texas 2 1: 7 .

18. Karski Tomasz, Karski Jacek (2019) Problem of Hips. Children - Dysplasia. Adults - "Imperfect Hips" and Arthrosis. Methods of Prophylaxis and Therapy in Every Age. Journal of Internal Medicine 2(1): 7-25. 


\section{Journal of Orthopedics \& Bone Disorders}

19. Krasuski M (2005) Algorytm postępowania diagnostyczno-leczniczego $\mathrm{w}$ zespołach bólowych kręgosłupa, Rehabilitacja Medyczna 9(3): 19-25.

20. Malawski S (1994) Własne zasady leczenia skolioz niskostopniowych w świetle współczesnych poglądów na etiologię i patogenezę powstawania skolioz, Chir Narz Ruchu i Ortop Pol 59(3): 189-197.

21. Mau H (1979) Zur Ätiopathogenese von Skoliose, Hüftdysplasie und Schiefhals im Säuglinsalter. Zeitschrift f Orthop 5: 601-605.

22. Mau H (1982) Die Atiopatogenese der Skoliose, Bücherei des Orthopäden, Band 33, Enke Verlag Stuttgart -110 .
23. Saji M, Leong JCY (1995) Increased femoral neckshaft angles in adolescent idiopathic scoliosis. Spine 20: 303-311.

24. Stokes IAF (1999) Studies in Technology and Informatics, Research into Spinal Deformities 2, IOS Press 1999, Amsterdam, Berlin, Oxford, Tokyo, Washington DC, 59: 1-385.

25. Tylman D (1995) Patomechanika bocznych skrzywień kręgosłupa, Wydawnictwo Severus, Warszawa, pp: 167. 